\title{
EFECTO DE PROBIÓTICOS EN EL ALIMENTO DE MARRANAS SOBRE LOS PARÁMETROS PRODUCTIVOS DE LECHONES
}

\author{
César Lázaro D. ${ }^{1}$, Fernando Carcelén C. ${ }^{2}$, Marlon Torres A. ${ }^{2}$ y Miguel Ara G. ${ }^{3}$
}

\section{Abstract}

Fifty sows of the PIC genetic line and their piglets were used to determine the effect of food additive probiotic (Saccharomyces cerevisiae $12 \times 10^{9} \mathrm{CFU} / \mathrm{g}$, Bacillus subtilis 15 $\mathrm{x} 10^{10} \mathrm{CFU} / \mathrm{g}$ and Bacillus coagulans $15 \times 10^{10} \mathrm{CFU} / \mathrm{g}$ ) added to conventional diets. The sows were randomly divided in two groups: Probiotic and Control. The Control group was fed with the gestation diet (MG) for 3 weeks prior to farrowing and the Probiotic group was fed with the MG diet supplemented with the probiotic. During this period the sows received a restricted amount of concentrate (2-3 kg/day/animal). The Control group during the lactation period was fed ad libitum with the lactation diet (ML) and the Probiotic group was fed with the ML diet supplemented with the probiotic. Body weight and feed intake was registered in sows while in piglets was recorded litter size, body weight at birth and at weaning, and mortality and morbidity. The results showed that the probiotic supplemented to the sow diet significantly affected birth body weight $(\mathrm{p}<0.05)$. Moreover, there were minor differences in piglet mortality and morbidity due to gastro enteric disorders.

Key words: probiotics, sow, piglet, Saccharomyces cerevisiae, Bacillus subtilis, Bacillus coagulans

\section{Resumen}

Cincuenta marranas de la línea PIC y sus lechones fueron utilizadas para determinar el efecto de un aditivo probiótico (Saccharomyces cerevisiae $12 \times 10^{9} \mathrm{CFU} / \mathrm{g}$, Bacillus subtilis $15 \times 10^{10} \mathrm{CFU} / \mathrm{g}$ y Bacillus coagulans $15 \times 10^{10} \mathrm{CFU} / \mathrm{g}$ ) añadido en dietas convencionales. Las marranas fueron divididas aleatoriamente en dos grupos: Probiótico y Testigo. Las dietas experimentales durante la gestación fueron: 1) Grupo testigo: dieta de marranas gestantes (MG) tres semanas previas al parto y 2) Grupo probiótico: MG suplementado con el aditivo probiótico. Durante este periodo las marranas fueron alimentadas de manera restringida (2-3 kg/día). La alimentación durante la lactación fue como sigue: 1) Grupo testigo: dieta de marranas lactantes (ML) y 2) Grupo probiótico: ML sin antibiótico y suplementado con el aditivo probiótico. El consumo fue ad libitum durante la lactación. En las marranas se registró el peso vivo y consumo de alimento, mientras que en lechones se resgistró el tamaño de camada y el peso al nacimiento y al destete, así como la mortalidad y morbilidad. Los resultados obtenidos muestran que el

\footnotetext{
${ }^{1}$ Práctica privada

${ }^{2}$ Laboratorio de Bioquímica, Nutrición y Alimentación, FMV-UNMSM

${ }^{3}$ Centro de Investigaciones IVITA, FMV-UNMSM
} 
probiótico adicionado a la dieta de las marranas afectó el peso de los lechones al nacimiento ( $p<0.05$ ); además, se encontraron diferencias en morbilidad y una diferencia marginal en la mortalidad de los lechones relacionada a problemas gastroentéricos.

Palabras clave: probióticos, marrana, lechón, Saccharomyces cerevisiae, Bacillus subtilis, Bacillus coagulans

\section{INTRODUCCIÓN}

Los lechones al nacer quedan expuestos a los microorganismos del ambiente que les rodea y, además, entran en contacto con las heces maternas que contienen bacterias que colonizan su tracto digestivo. Estas bacterias buscan un nicho adecuado, donde compiten e interaccionan entre sí, constituyendo finalmente una población relativamente estable y compleja que representa la microflora intestinal normal del lechón. No obstante, esta estabilidad puede ser alterada por cambios dietéticos o ambientales importantes (Radecki y Yokoyama, 1991; Conway, 1994; Jensen, 1998).

En el tracto gastrointestinal se encuentra normalmente un gran número de especies de bacterias comensales y patógenas; sin embargo, cuando se incrementa la cantidad de microorganismos patógenos se pueden producir alteraciones de la salud y muerte (Camacho, 1999).

Las principales formas de control de enfermedades entéricas se basan en el uso de antibióticos vía alimento; no obstante, su uso prolongado puede generar resistencia en cierto tipo de bacterias patógenas. Esto no sólo reduce el número de antimicrobianos disponibles en la industria para el control de infecciones bacterianas, sino que esta resistencia incrementa el riesgo para la salud humana (Mathew et al., 1998; Sala, 1992).

Los problemas entéricos, especialmente en lechones, son una de las principales causas de pérdidas económicas en la industria porcina. La totalidad de las granjas porcinas utiliza antibióticos de manera terapéutica y subterapéutica para controlar estos problemas, pero se debe incidir en la búsqueda de otros aditivos, que ofrezcan mejores o similares beneficios que los antibióticos y que a su vez no sean perjudiciales para los animales ni el hombre (Close, 2000; Sala, 1992).

Los probióticos han sido señalados como posibles reemplazos de los antibióticos. Estos han sido definidos como microorganismos vivos que ejercen un efecto benéfico para el tracto intestinal del hospedero, manteniendo y reforzando los mecanismos de defensa ante patógenos sin perturbar las funciones fisiológicas y bioquímicas normales (Fuller, 1989). Debido a esto, se planteó el presente estudio para evaluar el efecto de la suplementación de probióticos a marranas antes del parto y durante la lactación sobre la ganancia de peso de las marranas, el incremento en el consumo de alimento durante la lactación, el aumento de peso de los lechones al nacimiento y destete, y la disminución de la mortalidad y morbilidad debida a problemas entéricos.

\section{Materiales y Métodos}

El estudio se realizó en una granja porcina tecnificada ubicada en el valle del río Lurín, Lima, en el verano del 2004 durante 9 semanas. Se tuvo una temperatura ambiental máxima de $30.2^{\circ} \mathrm{C}$ y mínima de $21.8^{\circ} \mathrm{C}$.

Se utilizaron 50 marranas de 3 a 5 partos de la línea PIC en el último tercio de gestación, las cuales fueron divididas al azar en dos grupos de 25 animales cada uno: Probiótico y Testigo. Ambos grupos perma- 
necieron en el galpón de gestación hasta una semana antes de la fecha de parto donde pasaron a la sala de maternidad.

La alimentación de las marranas durante la última fase de la gestación fue de la siguiente manera:

- Grupo probiótico: Ración de marranas gestantes (MG) restringida $(2-3 \mathrm{~kg} /$ día $)$ dos veces al día por un periodo aproximado de 21 días. Se suplementó con los probióticos Saccharomyces cerevisiae (12 x $10^{9} \mathrm{CFU} / \mathrm{g}$ de excipiente), Bacillus subtilis $\left(15 \times 10^{10} \mathrm{CFU} / \mathrm{g}\right)$ y Bacillus coagulans $\left(15 \times 10^{10} \mathrm{CFU} / \mathrm{g}\right)$.

- Grupo testigo: Ración similar al grupo anterior pero sin la adición de probióticos.

Luego del parto, las marranas y los lechones permanecieron en las salas de maternidad con la alimentación siguiente:

- Grupo probiótico: Alimentación ad libitum con ración de marranas lactantes (ML) sin antibiótico y suplementada con los probióticos Saccharomyces cerevisiae $\left(12 \times 10^{9} \mathrm{CFU} / \mathrm{g}\right)$, Bacillus subtilis $\left(15 \times 10^{10} \mathrm{CFU} / \mathrm{g}\right)$ y Bacillus coagulans $\left(15 \times 10^{10} \mathrm{CFU} / \mathrm{g}\right)$ durante toda la etapa de lactación.

- Grupo testigo: Ración similar al grupo anterior pero sin la adición de probióticos.

La mezcla del producto se realizó en la granja al momento de la preparación del alimento, y se usó a razón de $2 \mathrm{~kg}$ por TM de alimento.

En la segunda etapa, las marranas comenzaron comiendo $1 \mathrm{~kg} /$ día y aumentaron de manera gradual hasta alcanzar los $7 \mathrm{~kg} /$ día. El alimento sobrante fue pesado al final del día para tener un registro del consumo real.

El manejo de los lechones fue el utilizado rutinariamente en la granja. Los lechones fueron pesados al nacer y se hizo una segun- da pesada dentro de las primeras 48 horas de vida para homogenizar el peso de los grupos, buscando que ambos lotes tuvieran un promedio similar en peso de camada y un mismo número de lechones. Se respetó el intercambio de lechones dentro del mismo grupo y los lechones excedentes fueron retirados y distribuidos con otras marranas que no estaban relacionadas con los tratamientos indicados. Los lechones fueron pesados al destete (20-21 días) por tercera y última vez.

Se empleó la prueba de ANOVA en el análisis de los datos de peso de los lechones al nacimiento, de la ganancia de peso de los lechones desde la homogenización hasta el destete y del consumo de alimento de las marranas durante la lactación. Los datos de mortalidad y morbilidad en lechones fueron evaluados con la prueba de Chi cuadrado. En el análisis de la variable peso de lechones al nacimiento se empleó un modelo de covarianza, ya que se detectó una pequeña pero significativa correlación entre tamaño de camada y peso de lechones al nacimiento.

\section{Resultados y Discusión}

\section{Tamaño de camada y peso al nacimiento}

Se encontró diferencia estadística significativa $(\mathrm{p}<0.05)$ a favor del grupo probiótico en el peso al nacimiento (Cuadro 1), tanto en el peso sin corregir como en el peso corregido por tamaño de camada. El peso tuvo que ser corregido al detectarse una correlación significativa entre el tamaño de la camada y el peso promedio de los lechones al nacimiento. En otro estudio utilizando un suplemento seco de levaduras (Saccharomyces cerevisiae) en marranas no se encontraron diferencias significativas en el peso de la camada al nacimiento (Jurgens et al., 1997).

La dieta de la cerda gestante tiene influencia directa sobre el desarrollo del feto. En las marranas ocurre un fenómeno llamado 
Cuadro 1. Tamaño de camada y peso al nacimiento de lechones provenientes de marranas con y sin suplementación de probióticos durante las tres semanas previas al parto

\begin{tabular}{|c|c|c|c|c|c|c|c|}
\hline \multirow{2}{*}{ Tratamientos } & \multicolumn{2}{|c|}{ Lechones } & \multirow{2}{*}{$\begin{array}{l}\text { Lechones } \\
\text { por camada } \\
\text { (n) }\end{array}$} & \multirow{2}{*}{$\begin{array}{c}\text { Peso de } \\
\text { camada } \\
\quad(\mathrm{kg})\end{array}$} & \multirow{2}{*}{$\begin{array}{c}\text { Peso por } \\
\text { lechón } \\
(\mathrm{kg})\end{array}$} & \multicolumn{2}{|c|}{ Significancia } \\
\hline & $\begin{array}{l}\text { Total de } \\
\text { nacidos }\end{array}$ & $\begin{array}{l}\text { Nacidos } \\
\text { vivos }\end{array}$ & & & & Real & Corregida $^{1}$ \\
\hline Probiótico & 288 & 285 & 11.5 & 16.9 & 1.47 & $0.0246^{*}$ & $0.0436^{*}$ \\
\hline Testigo & 299 & 292 & 12.0 & 16.2 & 1.35 & & \\
\hline
\end{tabular}

${ }^{1}$ Por tamaño de camada

* $(p<0.05)$

anabolismo gestacional por el cual una cerda preñada saca más ventaja de los alimentos que una cerda vacía, consiguiendo ganar peso durante la gestación y guardar energía, proteína, vitaminas y minerales para la fase lactante, y de esa forma la pérdida de peso en la lactación será proporcional con el peso ganado durante la gestación (Salmon, 1962).

Estas afirmaciones llevarían a suponer que la cerda debería ser sobrealimentada en la gestación para que pueda soportar mejor la lactación; sin embargo, hoy en día se sugiere usar raciones con más nutrientes (de lactación o preparto) que aumentar la cantidad de ración durante el final de gestación. En el presente trabajo se suministró la misma ración de marranas gestantes a los dos grupos, lo cual indicaría que el probiótico influyó en un mejor peso de los lechones al nacimiento.

\section{Consumo de alimento}

Las marranas del grupo probiótico consumieron $4.25 \mathrm{~kg}$ de alimento por día durante la lactación, en tanto que las marranas del grupo testigo consumieron $4.45 \mathrm{~kg} /$ día, no habiendo diferencia estadística significativa ( $>>0.05$ ) entre grupos. Estos resultados son similares a los obtenidos por Pichilingue (1994) quien concluyó que la administración de cul- tivos de levaduras (Saccharomyces cereviciae) 30 días antes del parto y durante la lactación no incrementó el consumo de alimento durante la lactación.

La temperatura ambiental en la sala de maternidad estuvo entre los 21 y $31^{\circ} \mathrm{C}$, valores superiores a los recomendados. La temperatura ideal para las cerdas es de 18 a 25 ${ }^{\circ} \mathrm{C}$ y es, sin duda, uno de los factores más importantes que causa la reducción en el consumo de ración. La marrana nota los cambios termales a través de los receptores nerviosos localizados en la piel y en el cerebro. Cuando éstos son activados, estimulan a la hipófisis que secreta ACTH, la cual estimula las glándulas suprarenales para la liberación de adrenalina y noradrenalina. Estas sustancias son responsables por las alteraciones físicas y metabólicas indispensables para mantener la temperatura corporal constante. En un momento de estrés calórico, hay una elevación de adrenalina y una disminución de noradrenalina causando un aumento del flujo de sangre en la piel y reducción del flujo sanguíneo en los órganos internos. Este flujo reducido de sangre visceral perjudica la digestión de los alimentos y la generación de energía para los procesos productivos como ganancia de peso y producción leche (Black et al.,1993). 


\section{Ganancia de peso de los lechones}

Los lechones del grupo probiótico tuvieron una ganancia de peso desde la homogenización hasta el destete de $3.43 \mathrm{~kg}$ y los del grupo testigo de $3.80 \mathrm{~kg}$, no habiendo diferencia significativa entre grupos $(p>0.05)$.

La literatura señala resultados contradictorios sobre la ganancia de peso con el uso de probióticos (Jurgens et al., 1997; Pichilingue, 1994). Sin embargo, en esos estudios, la administración y composición de los probióticos (Saccharomyces cereviciae y bacterias ácido lácticas) fueron diferentes a las usadas en este trabajo.

\section{Mortalidad en lechones}

En el grupo testigo murieron 10 lechones $(3.6 \%)$ y en el grupo probiótico murieron $7(2.5 \%)$. De allí, el número de lechones muerto por diarreas fue de 3 y 1 , y por desnutrición fue de 5 y 1 en los grupos testigo y probiótico, respectivamente, no habiendo diferencia estadística entre grupos $(\mathrm{p}>0.05)$.

$\mathrm{Al}$ analizar en conjunto los desórdenes gastrointestinales (desnutrición y problemas diarreicos) se tuvo que el grupo testigo tuvo 8 lechones afectados, a diferencia del grupo probiótico donde ocurrió en 2 lechones, siendo estos valores casi significativos ( $\mathrm{p}=0.054$ ). Pichilingue (1994) encontró diferencias significativas en la ocurrencia de muertes debidas a desórdenes gastroentéricos y diarreas entre el grupo testigo y el de probióticos, pero hay que considerar que en ese trabajo se suplementó el probiótico de manera directa a los lechones.

La disminución de la mortalidad, la incidencia de diarreas y la presencia de E. coli en las heces ha sido observada en cerdos en crecimiento alimentados con dietas que contenían Bacillus sp. (Bonomi, 1992; Succi et al., 1995; Adami et al., 1997).

\section{Morbilidad en lechones}

Los casos de morbilidad en lechones incluyeron aquellos que presentaron algún problema digestivo y alcanzaron el destete. En el grupo probiótico se registró la ocurrencia de 3 casos de diarrea y en el grupo testigo de 16 casos $(\mathrm{p}<0.05)$.

El manejo sanitario de la granja afectó estos resultados. Las salas de maternidad eran higienizadas pero no eran sometidas a un adecuado descanso postdestete. Además, sólo se aplicaba antibiótico parenteral a los animales que enfermaban, pero no a la camada entera o a la totalidad de la sala, práctica que es muy común en algunas granjas porcinas del medio.

\section{Conclusiones}

- La administración de probióticos en marranas gestantes mejoró el peso de los lechones al nacimiento $(\mathrm{p}<0.05)$ pero no afectó la ganancia de peso ni la mortalidad de los lechones relacionada a trastornos gastroentéricos (desnutrición y diarreas).

- El consumo de alimento de las marranas durante la lactación no fue afectado por la suplementación del probiótico.

\section{Literatura Citada}

1. Adami, A.; A. Sandrucci; V. Cavazzoni. 1997. Piglets fed from birth with the probiotica Bacillus coagulans as additive. Zootechnical and microbiological aspects. Ann. Microbiol. Enzimol. 47: 139-149.

2. Black, J.L.; B.P. Mullan; M.L. Lorschy; L.R. Giles. 1993. Lactation in the sow during heat stress. Livest. Prod. Sci. 35: 153-157.

3. Bonomi, A. 1992. Probiotics in pig breeding. Results from the use of 
Bacillus subtilis and Bacillus licheniformis. Experimental contribution. Riv. Soc. Ital. Sci. Aliment. 21: 481-499.

4. Camacho, C. 1999. Enfermedades entéricas en los cerdos. Mundo Avícola y Porcino 31: 39-42.

5. Close, W.H. 2000. Producing pigs without antibiotic growth promoters. Advances in Pork Production 11: 47- 56.

6. Conway, P.L. 1994. Proc. VI International Symposium on Digestive Physiology in Pigs. p 231-240. EAAP Publication. Ban Doberan, Germany.

7. Fuller, R. 1989. Probiotics in man and animals. J. Appl. Bacteriol. 66: 365-378.

8. Jensen, B.B. 1998. Gut environment of pigs. J. Anim. Feed Sci. 7: 45-64.

9. Jurgens, M.H.; R.A. Rikabi; D.R. Zimmerman. 1997. The effect of dietary dry yeast supplement on performance of sows during gestation-lactation and their pigs. J. Anim. Sci. 75: 593-597.

10. Mathew, A.G.; G.W. Upchurch; S.E.

Chattin. 1998. Incidence of antibiotic resistance in fecal Escherichia coli isolated from commercial swine farms. J. Anim. Sci. 76: 429-434.

11. Pichilingue, N. 1994. Uso de probióticos en la marrana y su camada durante el periodo pre parto, lactación y post destete. Tesis de Bachiller. Univ. Nacional Agraria La Molina. Lima, Perú. $90 \mathrm{p}$.

12. Radecki, S.V.; M.T. Yokoyama. 1991. Swine nutrition. p 439-447. E.R. Miller; D.E. Ullrey; A.J. Lewis (eds). Butterworth Heinemann. Boston, USA.

13. Sala, C.G. 1992. Antibacteriales de uso terapéutico: usos, mal uso y abuso. Rev. Cien. Vet. 8: 151-155.

14. Salmon, R. 1962. Nutrition of the sow during pregnancy. En: Nutrition of pigs and poultry. p 207-223. J.T. Morgan; D. Lewis (eds). Butterworths. London, UK.

15. Succi, G.; A. Sandrucci; A. Tamburini; A. Adami; V. Cavazzoni. 1995. Effects of using a new strain of Bacillus coagulans as a probiotic on the performance of piglets. Riv. Suinicol. 36: 59-63. 